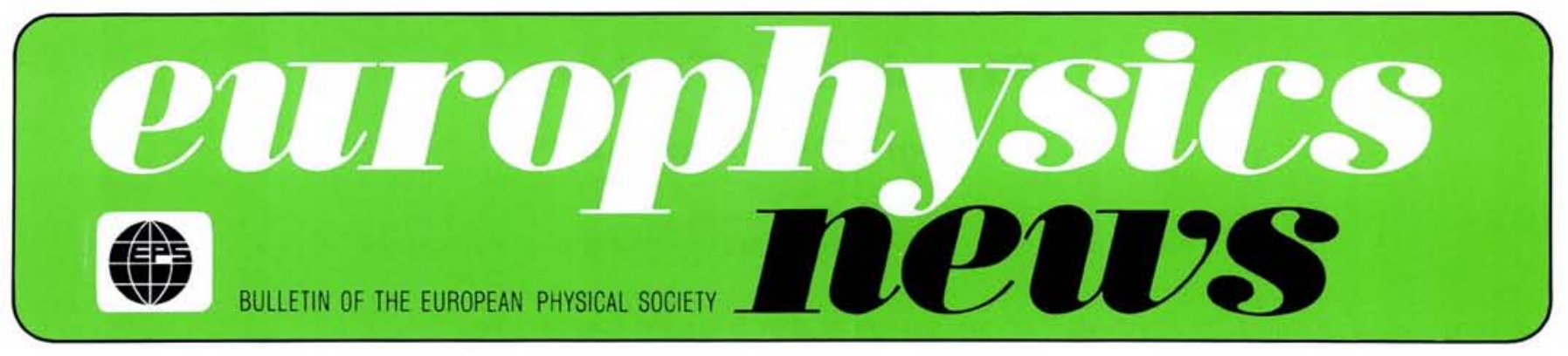

\title{
From the President
}

\section{The State of the Society}

\section{A.R. Mackintosh}

The revolution in science out of which modern physics developed, was begun in Europe and, as the programme of the 5th General Conference of EPS illustrates, that originality and quality which have been a tradition of European physics, are still strongly in evidence in current research. It is particularly gratifying and appropriate that in Istanbul, Professor Dirac, one of the primary creators of that revolution and an honorary member of our Society, will be giving his views on the development of modern physics. Noone is better able to assess the transformation that has taken place.

In many European countries, conditions for physics are not favourable at present. Economic recession has reduced funding for research and, more seriously, lack of employment opportunities can prevent even the most able of our younger colleagues from continuing their work. As we are all aware, without a steady influx of new talent and ideas, our subject will gradually decline.

In these circumstances, the EPS has a particularly important role to play, but also servere difficulties to contend with. Our efforts to co-ordinate activities within physics at many levels in Europe, contribute to a more effective use of limited resources. Common research projects, in-

\section{Reports of Istanbul \\ Copies of the abstracts of the papers prepared for Istanbul may be bought from the Secretariat in Geneva for Sw.Fr. 40.- \\ Proceedings of the 5th General Con- ference will be published at the end of the year. Participants receive a copy automatically; otherwise the price to IOMs is Sw.Fr. 50.-; to libraries Sw.Fr. 90.-. An order form will be in- cluded with the next issue of Europhy- sics News.}

ternational conferences, and interchanges of scholars and students all promote an increase in productivity and a raising of standards within European physics. But economic difficulties are also reflected in the Society, and the Council has recommended the Executive Committee to form an Advisory Committee on Finance, with a view to increasing our income so that we can initiate further actions that benefit the physics community.

One area in which the Society has been active recently is publications. The European Conference Abstracts series has been reconstituted on a more comprehensive and satisfactory basis, and the European Journal of Physics has been successfully launched, in collaboration with the Institute of Physics. The two publications, which are indispensable to respectively, research physicists and university teachers, fill a long-standing lacuna in the European physics literature. They should be available in every relevant physics library and our members would be making an important contribution to the Society if they ensured that, even though budgets are under pressure everywhere, their own libraries were subscribers. Individual subscriptions are also most welcome. Discussions are now proceeding very intensively on the creation, on a broad European basis, of a letters journal, for the rapid communication of important new results.

The physics community throughout the world is becoming increasingly concerned about restrictions on the scientific and personal freedom of our colleagues in many lands, and increasingly active in attempting to counter such violations of professional and human rights. Because of the composition of EPS, we are in some respects in a unique position to exert an influence on the situation, especially within Europe. The Council believes that it is important that we use this influence responsibly and impartially, and has instructed the Executive Committee to form an Advisory Committee on Scientific Freedom. This Committee, whose Chairman is Professor John Charap, will investigate allegations of infringements of the scientific and human rights of physicists, and recommend appropriate action to the President and Executive.

When one considers the progress of most scientific societies in their early phases, the achievements of the EPS during the first dozen years are remarkably impressive. We have had the advantages of filling an obvious need and reflecting the spirit of European collaboration which is manifest in many different areas. But the impact which the Society has made on European physics would not have been possible without the devoted and constructive efforts of a relatively small, though growing fraction of European physicists.

The trend towards increased international collaboration, with large common facilities for physics research, ensures that the EPS will inevitably come to play an increasingly important role in the future. Those of us who are responsible for directing the affairs of the Society at present welcome the interest of all who wish to help define our ideals and goals for the coming years, and particularly the active assistance of those who are willing to help turn our aspirations into reality.

\section{Contents}

State of the Society

Physics in Turkey

Tandem Mirror Approach to Magnetic Fusion

Primordial Helium

Hydrogen Production by Water Electrolysis

Solar Physicists in Oxford

Divisional News 